\title{
BMJ Open Establishment of blood pressure nomograms representative for Egyptian children and adolescents: a cross- sectional study
}

\begin{abstract}
Ali M El-shafie, ${ }^{1}$ Fady M El-Gendy, ${ }^{1}$ Dalia M Allhony, ${ }^{1}$ Wafaa Moustafa M Abo El Fotoh, ${ }^{1}$ Zein A Omar, ${ }^{1}$ Mohamed A Samir, ${ }^{1}$ Wael A Bahbah, ${ }^{1}$ Sameh Abdallah Abd el naby, ${ }^{1}$ Rania S El Zayat, ${ }^{1}$ Nahla M Said Abd El Hady, ${ }^{1}$ Basim A El Gazar, ${ }^{1}$ Mohamed A Zannoun, ${ }^{2}$ Zeinab A Kasemy, ${ }^{3}$ Ahmed N El-Bazzar, ${ }^{4}$ Mohamed Abd El-nour Abd El-Fattah, ${ }^{4}$ Amir A Abd El-monsef, ${ }^{4}$ Amir M Kairallah, ${ }^{4}$ Hythem M Raafet, ${ }^{4}$ Ghada M Baz, ${ }^{4}$ Amany Gaber Salah, ${ }^{4}$ Walaa S Galab ${ }^{4}$
\end{abstract}

To cite: El-shafie AM, ElGendy FM, Allhony DM, et al. Establishment of blood pressure nomograms representative for Egyptian children and adolescents: a crosssectional study. BMJ Open 2018;8:e020609. doi:10.1136/ bmjopen-2017-020609

- Prepublication history and additional material for this paper are available online. To view these files, please visit the journal online (http://dx.doi org/10.1136/bmjopen-2017020609).

Received 15 November 2017 Revised 6 June 2018 Accepted 12 June 2018

\section{Check for updates}

(c) Author(s) (or their employer(s)) 2018. Re-use permitted under CC BY-NC. No commercial re-use. See rights and permissions. Published by BMJ.

For numbered affiliations see end of article.

\section{Correspondence to} Professor Wafaa Moustafa M Abo El Fotoh;

wafaamoustafa60@yahoo.com

\section{ABSTRACT}

Objective To define nomograms for blood pressure in

Egyptian children and adolescents.

Methods and study design A total of 60025 Egyptian children from birth to 19 years were enrolled in this crosssectional randomised study from December 2015 to March 2017. They were selected from diverse geographical districts in Egypt. Healthy children who fulfilled the inclusion criteria, which included good nutritional history, absence of fever or documented underlying disease at the time of examination, no evidence of haemodynamically significant illness, and no antihypertensive drugs or other chronic drug administration, were included in the study. Body weight, recumbent length (for less than 24 months) and height (from 2 years to 19 years), and blood pressure were measured using standard mercury sphygmomanometers.

Results Blood pressure increases with age in both boys and girls. The 90th percentile of systolic and diastolic blood pressure among Egyptian children was different from other ethnic populations (American and Turkish children) in both sexes. Systolic and diastolic blood pressure showed a positive correlation with weight and height in both sexes $(p<0.001)$.

Conclusion We assumed that normal blood pressure curves should be used cautiously during childhood, and it is recommended that every population have its own normal standard curve to define measured blood pressure levels in children. These centiles increased our knowledge and awareness of normal blood pressure among Egyptian children and adolescents. The percentiles will distinguish children and young adolescents with increased blood pressure and will be of value to both medical practice and scientific research.

\section{INTRODUCTION}

Blood pressure (BP) is regulated by an array of physiological mechanisms, including neuronal and hormonal impulses of the

\section{Strengths and limitations of this study}

- The study has appropriate sample size estimation.

- Another strength of the study is its multicentre representation of diverse geographical districts in Egypt.

- The study used standard accurate mercury sphygmomanometers to record blood pressure (BP).

- BP measurements were obtained in usual settings for children such as school and home, overcoming the phenomenon of white coat hypertension.

- This is the first study to specify BP values and curves in Egyptian boys and girls.

heart, blood vessels, brain, renal system and digestive tissues. ${ }^{1}$ Age is considered one of the main determinants of $\mathrm{BP}$ values. $\mathrm{BP}$ increases more and more with age and more precipitously during puberty. ${ }^{2}$ The additional contributing factor is sex, as the occurrence of hypertension is higher among boys than girls. BP values, particularly beyond 12-14 years, are greater in boys than girls, and this is similar to the findings in adults. ${ }^{3}$

As with adults, BP in children is determined by both height and weight; however, in the paediatric setting, the fraction attributable to height may be physiological, and may not be influenced by excess weight. ${ }^{4}$

There is considerable proof that BP measured in childhood predicts future BP. Those with BP levels in the higher sections of the distribution curve have a tendency to sustain this level over time, which is uncovering of BP tracking. ${ }^{5}$ Hence, BP estimation has to be included in regular physical assessments during childhood and elucidated 
Table 1 Age groups with the mean weight and height for both boys and girls

\begin{tabular}{|c|c|c|c|c|c|c|c|c|c|c|}
\hline \multirow[b]{2}{*}{$\begin{array}{l}\text { Age } \\
\text { (years) }\end{array}$} & \multicolumn{5}{|l|}{ Boys } & \multicolumn{5}{|l|}{ Girls } \\
\hline & $\mathrm{n}$ & $\begin{array}{l}\text { Mean } \\
\text { weight } \\
\text { (kg) }\end{array}$ & Deviations & $\begin{array}{l}\text { Mean } \\
\text { height } \\
\text { (cm) }\end{array}$ & Deviations & $\mathrm{n}$ & $\begin{array}{l}\text { Mean } \\
\text { weight } \\
\text { (kg) }\end{array}$ & Deviations & $\begin{array}{l}\text { Mean } \\
\text { height } \\
\text { (cm) }\end{array}$ & Deviations \\
\hline 1 & 1344 & 10 & 0.10991 & 75 & 2.43733 & 1348 & 9 & 0.12203 & 73 & 2.78564 \\
\hline 2 & 5716 & 13 & 0.11425 & 87 & 3.29913 & 5685 & 12 & 0.12523 & 85 & 3.57202 \\
\hline 3 & 2406 & 15 & 0.12023 & 95 & 3.75950 & 2333 & 15 & 0.12899 & 94 & 3.77889 \\
\hline 4 & 2223 & 17 & 0.12603 & 103 & 4.13071 & 2148 & 17 & 0.13145 & 102 & 4.28939 \\
\hline 5 & 2199 & 19 & 0.13555 & 109 & 4.77980 & 2135 & 18 & 0.14005 & 109 & 4.65815 \\
\hline 6 & 1259 & 21 & 0.14399 & 115 & 4.96748 & 1096 & 21 & 0.15255 & 114 & 5.31711 \\
\hline 7 & 1288 & 23 & 0.15487 & 121 & 5.34940 & 1082 & 23 & 0.16145 & 120 & 5.39606 \\
\hline 8 & 1290 & 25 & 0.16588 & 127 & 5.86112 & 1050 & 25 & 0.17122 & 126 & 5.76132 \\
\hline 9 & 1244 & 28 & 0.17211 & 132 & 5.94979 & 1026 & 29 & 0.17455 & 132 & 6.03576 \\
\hline 10 & 1283 & 31 & 0.17781 & 137 & 6.28514 & 1088 & 32 & 0.17933 & 138 & 6.26325 \\
\hline 11 & 1305 & 35 & 0.18022 & 142 & 6.93480 & 1030 & 35 & 0.18015 & 144 & 7.22371 \\
\hline 12 & 1254 & 39 & 0.18253 & 148 & 7.11191 & 1047 & 40 & 0.18244 & 151 & 6.91346 \\
\hline 13 & 1284 & 44 & 0.18972 & 155 & 7.43915 & 1063 & 44 & 0.18475 & 156 & 7.02548 \\
\hline 14 & 1247 & 48 & 0.18881 & 162 & 7.69325 & 1053 & 47 & 0.18952 & 159 & 6.93250 \\
\hline 15 & 1299 & 50 & 0.19035 & 168 & 7.64829 & 1036 & 49 & 0.19134 & 161 & 6.82588 \\
\hline 16 & 1261 & 52 & 0.19683 & 172 & 7.88363 & 1049 & 52 & 0.19735 & 162 & 6.52740 \\
\hline 17 & 1248 & 53 & 0.19874 & 175 & 7.51475 & 1.073 & 52 & 0.20175 & 162 & 6.39211 \\
\hline 18 & 1210 & 53 & 0.20051 & 175 & 7.31851 & 1034 & 54 & 0.24520 & 162 & 6.15977 \\
\hline 19 & 1243 & 54 & 0.20472 & 176 & 7.25872 & 1046 & 54 & 0.25780 & 162 & 6.47949 \\
\hline Total & 31603 & - & & - & & 28422 & - & & - & \\
\hline
\end{tabular}

according to the standards of the normal childhood BP distribution curve. ${ }^{6}$ The distribution of BP levels and hypertension differs in various racial and ethnic clusters. This difference is determined by multiple factors, both genetic and environmental determinants. Grounded on these disparities, reference standards established for one population may not be appropriate in others. ${ }^{2}$ 7-12 Regional native reference norms are needed to evaluate estimated BP values. Thus, this work aimed to establish representative BP percentile charts for Egyptian children and adolescents for the early detection and accurate recognition of BP fluctuations and/or abnormalities.

\section{METHODS AND DESIGN \\ Participants}

Egypt is a great country consists of 27 governorates. The multistage random sampling technique was used to conduct the study. Out of the 27 governorates, 2 big governorates from Upper Egypt and 6 big governorates from Lower Egypt were chosen. Then 20 districts and cities were randomly chosen out of the previously chosen governorates. Within the districts and cities, facilities including a nursery, Primary care units (PCU), vaccination centres, basic education schools and secondary training schools were counted, and 160 facilities in the selected 8 governorates were randomly chosen, as demonstrated in the sampling flow chart (online supplementary file). The study was conducted 3 days a week. The crowded days were taken in order to obtain and gather more information. In the nursery, primary health care (PHC) units and vaccination centres, the study was conducted in the morning in private rooms immediately after receiving medical advice or vaccination. In schools, the measurements were taken between the educational courses, during breaktime. The total number of children who were eligible for the study was 64500 . After applying the inclusion and exclusion criteria, 4475 children were excluded, giving a final total sample of 60025 . The children who fulfilled the criteria of the study from birth to 19 years were examined from December 2015 to March 2017, and are representative of the children in Egypt. Verbal consents were obtained from parents or guardians, and they were informed about the objectives of the study, its benefits and the absence of any risk associated with the participation of their children.

\section{Inclusion and exclusion criteria}

Healthy children who fulfilled the inclusion criteria, which included good nutritional history, absence of fever or documented underlying disease at the time of examination, no evidence of haemodynamically significant 


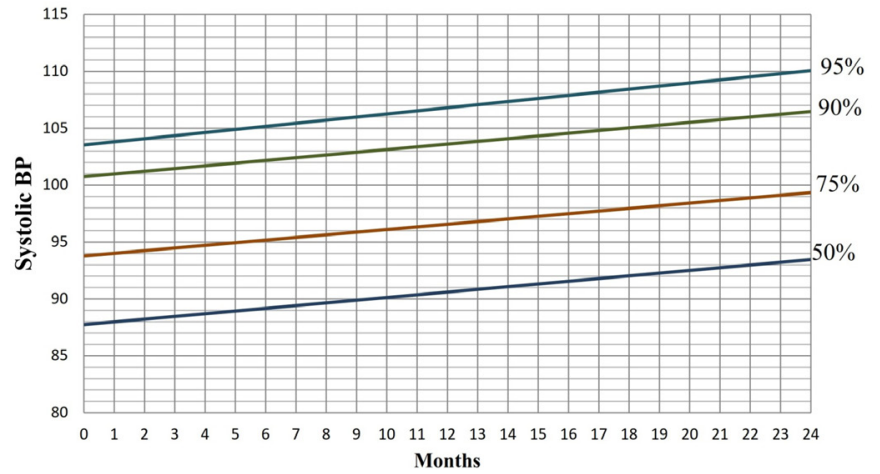

Figure 1 Smoothed percentile of systolic blood pressure (BP) measurements in Egyptian boys from birth to 24 months of age.

illness such as congenital heart disease, or thoracic surgery, and no antihypertensive drugs or other chronic drug administration, were included. Children and adolescents with obesity were excluded. There were 807 obese children: 338 boys ( 9 from birth to 1 year and 329 from 1 year to 19 years) and 469 girls (12 from birth to 1 year and 457 from 1 year to 19 years).

\section{Measurements and data collection}

Records were assembled by qualified medical personnel. Weight, recumbent length (for less than 24 months) and height (from 2 years to 19 years) were measured, as well as BP. All BP measuring instruments were calibrated on a daily basis. Standard mercury sphygmomanometers (Model 1002/Presameter, Riester, Germany) with different cuff sizes were used for all measurements. ${ }^{13}$ In the present study, 60025 children were examined in 160 facilities in 8 governorates using the standard mercury sphygmomanometer. Training was conducted with the working team for 3 days, along with invited children of different age and gender. This training was followed by testing to assess the degree of response to training and the quality of the measurement. The mean differences among the

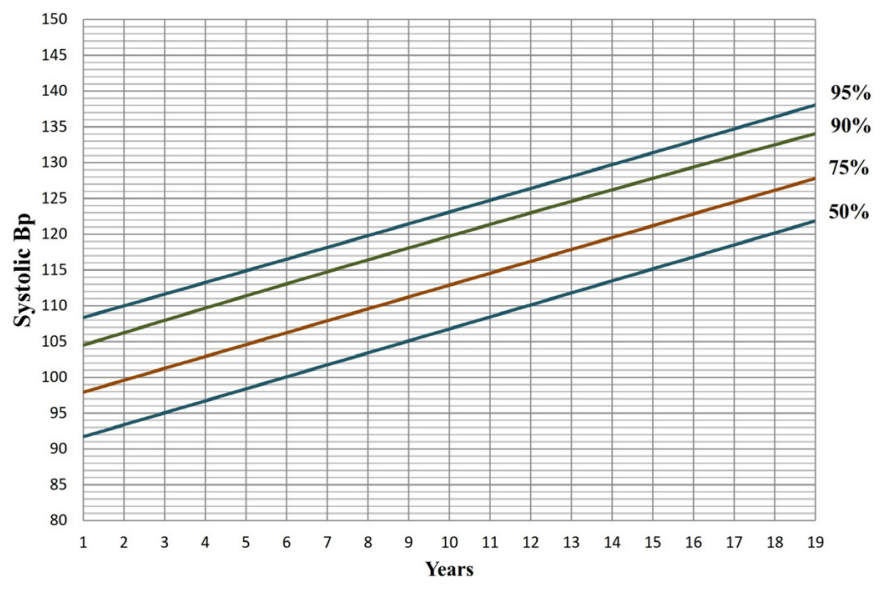

Figure 2 Smoothed percentile of systolic blood pressure (BP) measurements in Egyptian boys from 1 to 19 years of age.

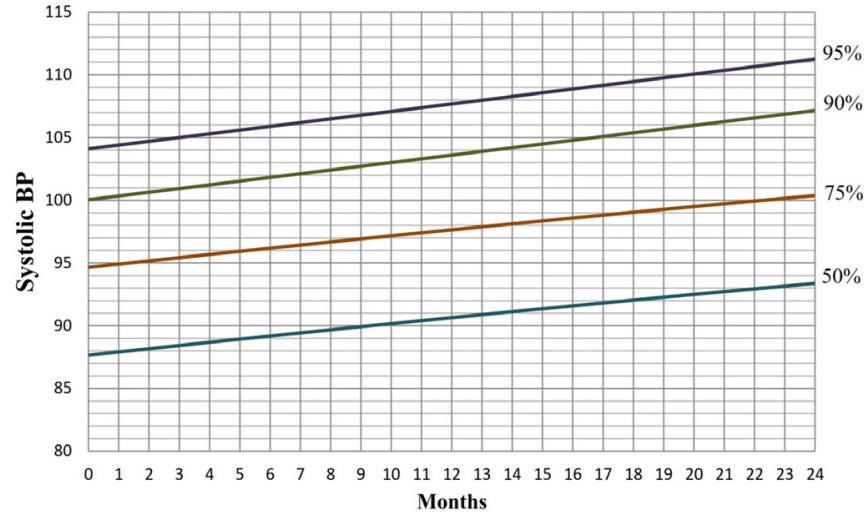

Figure 3 Smoothed percentile of systolic blood pressure (BP) measurements in Egyptian girls from birth to 24 months of age.

working observer team on 100 children of different age and sex as a pilot study were small $( \pm 0-3 \mathrm{~mm} \mathrm{Hg})$.

The evaluation of the effectiveness of site visits was concluded, and the use of an electronic device for internal standardisation was described. In all facilities, reliability was high and comparable with the observers at the coordinating centre. All the participants were in a comfortable sitting position (infants in supine), in a wakeful state with their right arm fully exposed and resting on a supportive surface at the heart level. A cuff bladder was selected with a width that covered at least two-thirds of the upper arm (the distance between the olecranon and acromion) and a length beyond at best $80 \%$ of the biceps' circumference. The cuff was inflated to a level that occluded the pulse at the wrist, the stethoscope was placed over the antecubital fossa, and then the cuff was deflated. The onset of the first Korotkoff (K1) sound was used as a measure for systolic blood pressure (SBP); K4 diastolic blood pressure (DBP) was used as the standard for infants and children 3-12 years of age; and K5 DBP was used as the standard for adolescents 13-19 years of age. Two readings were recorded with an interval of 5-10 min in-between and the mean was calculated for the final analysis.

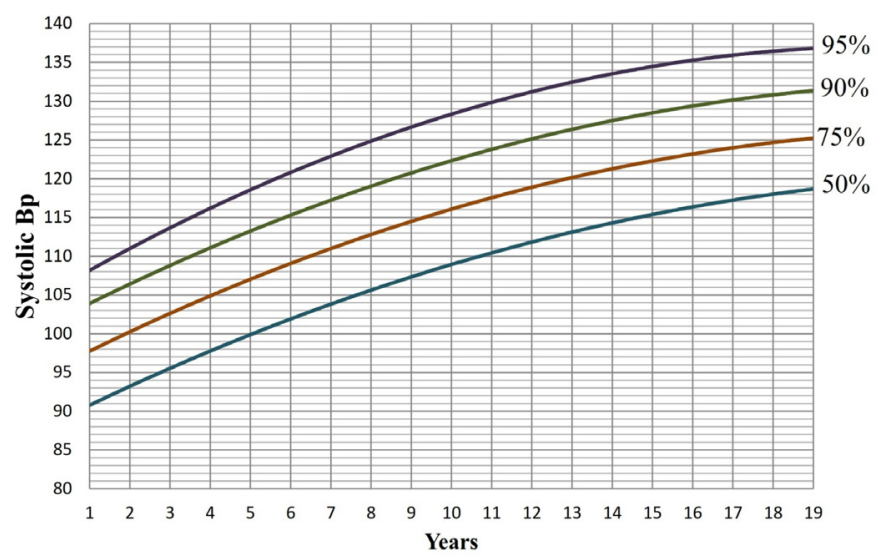

Figure 4 Smoothed percentiles of systolic blood pressure (BP) measurements in Egyptian girls from 1 to 19 years of age. 


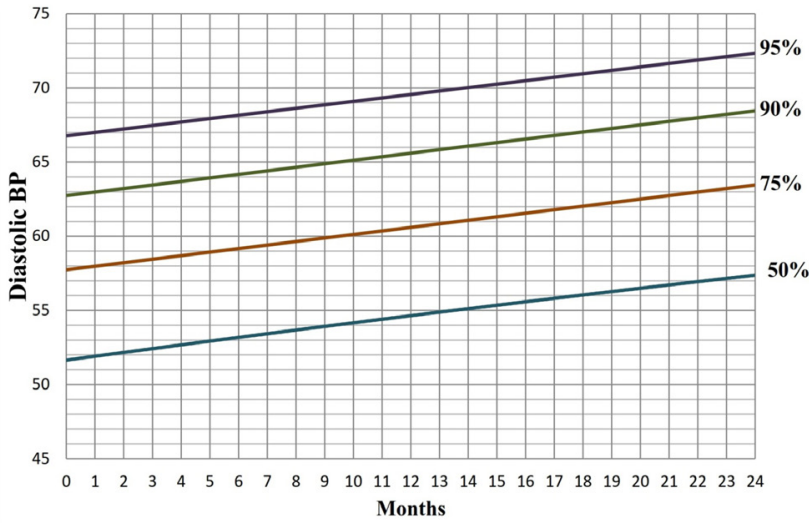

Figure 5 Smoothed percentiles of diastolic blood pressure (BP) measurements in Egyptian boys from birth to 24 months of age.

\section{Patient and public involvement}

To improve the relevance of research, research orientation that includes patients and the public is vital. The authors aimed to identify the most important research priorities of patients, caregivers and healthcare providers (paediatricians, nurses and dietitians) for BP measurement. A paper-based survey asked patients, caregivers and care providers to submit their unanswered questions on BP measurement. A priority-setting process then ranked the final top 4 research priorities during an inperson meeting. There were 200 respondents who submitted 360 questions after exclusions. Of the respondents, $50 \%$ were patients or caregivers, $60 \%$ lived in urban areas, the caregivers were aged 23-45 years, and $85 \%$ were women. The 360 questions were reduced to 20 unique questions, and from this list the top 4 research questions that were prioritised included charts that can easily determine normal and abnormal levels of BP, education tools and technologies to improve patient motivation and health behaviours, evaluation of the optimal role of different healthcare providers and caregivers in supporting patients with abnormal change in BP, and development of

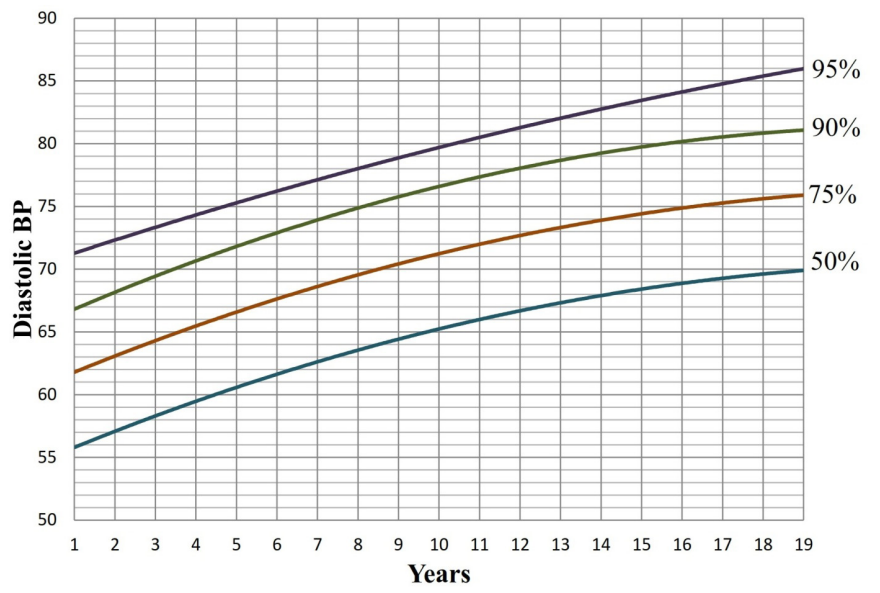

Figure 6 Smoothed percentiles of diastolic blood pressure (BP) measurements in Egyptian boys from 1 to 19 years of age.

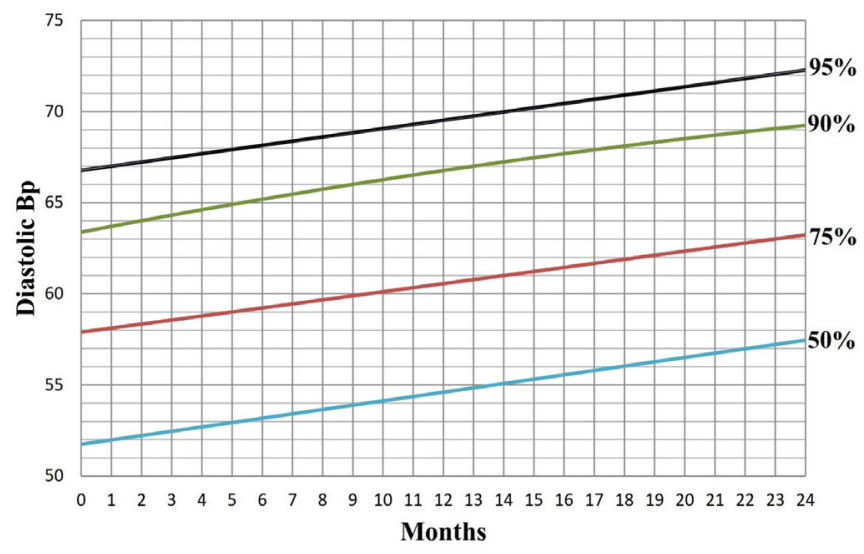

Figure 7 Smoothed percentiles of diastolic blood pressure (BP) measurements in Egyptian girls from birth to 24 months of age.

healthy lifestyle modifications to reduce changes in BP. In areas that are of high priority for BP measurement, these priorities can be used to guide clinicians, researchers and funding bodies for patients, caregivers and healthcare providers. This also highlights priority areas for improved communication, knowledge transfer and delivery of patient-centred care. The children $(n=100)$ of different age and sex who were subjected to BP measurement by observers to assess the degree of response to training and quality of measurement participated in setting the priorities of the research either on their own or by their caregiver. Some of these children, as well as caregivers, in addition to a large number of children from different sites in different governorates, helped us distribute the brochures that encourage $\mathrm{BP}$ measurement and invite their peers, for example, from schools, clubs and others, to come to the facilities where BP measurements were conducted. Also, we responded to some of the opinions of the caregivers, especially in addressing concerns with the great governorates and how to make communication with every single governorate, especially that for some of

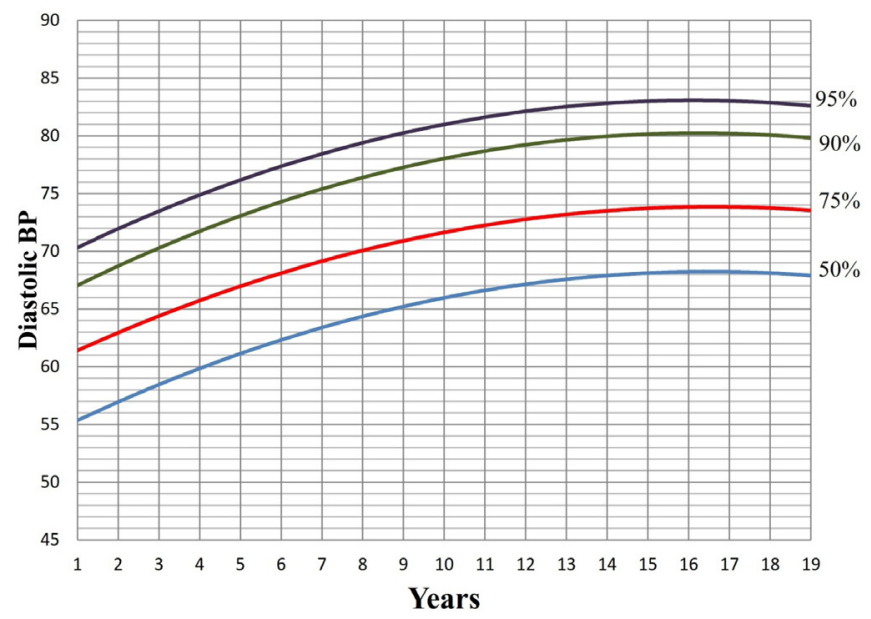

Figure 8 Smoothed percentiles of diastolic blood pressure (BP) measurements in Egyptian girls from 1 to 19 years of age. 
Table 2 Exact percentile values for systolic blood pressure (SBP) measurements in Egyptian boys from birth to 24 months of age

\begin{tabular}{|c|c|c|c|c|}
\hline \multirow[b]{2}{*}{ Age (month) } & \multicolumn{4}{|c|}{ Percentile values for SBP (mm Hg) } \\
\hline & $50 \%$ & $75 \%$ & $90 \%$ & $95 \%$ \\
\hline 0 & 88 & 94 & 101 & 104 \\
\hline 1 & 88 & 94 & 101 & 104 \\
\hline 2 & 88 & 94 & 101 & 104 \\
\hline 3 & 88 & 94 & 101 & 104 \\
\hline 4 & 89 & 95 & 102 & 105 \\
\hline 5 & 89 & 95 & 102 & 105 \\
\hline 6 & 89 & 95 & 102 & 105 \\
\hline 7 & 89 & 95 & 102 & 105 \\
\hline 8 & 90 & 96 & 103 & 106 \\
\hline 9 & 90 & 96 & 103 & 106 \\
\hline 10 & 90 & 96 & 103 & 106 \\
\hline 11 & 90 & 96 & 103 & 106 \\
\hline 12 & 91 & 97 & 104 & 107 \\
\hline 13 & 91 & 97 & 104 & 107 \\
\hline 14 & 91 & 97 & 104 & 107 \\
\hline 15 & 91 & 97 & 104 & 108 \\
\hline 16 & 92 & 98 & 105 & 108 \\
\hline 17 & 92 & 98 & 105 & 108 \\
\hline 18 & 92 & 98 & 105 & 108 \\
\hline 19 & 92 & 98 & 105 & 109 \\
\hline 20 & 93 & 98 & 106 & 109 \\
\hline 21 & 93 & 99 & 106 & 109 \\
\hline 22 & 93 & 99 & 106 & 110 \\
\hline 23 & 93 & 99 & 106 & 110 \\
\hline 24 & 93 & 99 & 106 & 110 \\
\hline
\end{tabular}

us it was the first time to visit some of the involved governorates. Their help will never be forgotten, so besides our role in the dissemination of the results through telephone calls to inform them about their BP measurements, we will also organise an event or a special day in every governorate to thank them and to address the main health problems they have.

\section{Statistical analysis}

With a view to accomplishing the reference standard curves (smoothed percentiles), logarithmic and semilogarithmic adjustments of SBP and DBP were statistically valued by regression analysis for different percentiles (50th, 75th, 90th and 95th), and the correlation coefficients of SBP and DBP with weight and height were processed. The statistical analysis was accomplished using IBM SPSS Statistics V.20 and ages were verified in complete years. The benchmarks used to certify the normal (50th90th percentile), high-normal (90th-95th percentile) and high BP ( $>95$ th percentile) were comparable with
Table 3 Exact percentile values for systolic blood pressure (SBP) measurements in Egyptian boys from 1 to 19 years of age

\begin{tabular}{ccccc}
\hline & \multicolumn{4}{l}{ Percentile values for SBP $(\mathbf{m m ~ H g})$} \\
\cline { 2 - 5 } Age (year) & $\mathbf{5 0 \%}$ & $\mathbf{7 5 \%}$ & $\mathbf{9 0 \%}$ & $\mathbf{9 5 \%}$ \\
\hline 1 & 91 & 97 & 104 & 107 \\
2 & 93 & 99 & 106 & 110 \\
3 & 95 & 102 & 108 & 112 \\
4 & 97 & 103 & 110 & 114 \\
5 & 99 & 105 & 112 & 115 \\
6 & 101 & 107 & 113 & 117 \\
\hline 7 & 102 & 108 & 115 & 119 \\
\hline 8 & 103 & 110 & 116 & 120 \\
\hline 9 & 105 & 111 & 118 & 121 \\
10 & 107 & 113 & 120 & 123 \\
\hline 11 & 109 & 115 & 122 & 125 \\
12 & 110 & 116 & 123 & 126 \\
12 & 111 & 117 & 124 & 127 \\
\hline 14 & 112 & 118 & 125 & 129 \\
\hline 15 & 114 & 120 & 127 & 130 \\
\hline 16 & 116 & 122 & 128 & 132 \\
\hline 17 & 118 & 124 & 131 & 135 \\
\hline 18 & 121 & 127 & 133 & 137 \\
\hline 19 & 123 & 129 & 135 & 139 \\
\hline
\end{tabular}

the Report of the Second Task Force on Blood Pressure Control in Children in $1987 .{ }^{13}$

\section{RESULTS}

A total of 60025 Egyptian children, 31603 boys (52.6\%) and 28422 girls $(47.4 \%)$, from birth to 19 years of age were examined in this study on SBP and DBP (table 1). Various smoothed percentile charts of SBP and DBP for both sexes according to age are shown in figures 1-8. In the present study, SBP and DBP rose steadily with age in both boys and girls. The mean annual increase in SBP for boys was $1.68 \mathrm{~mm} \mathrm{Hg}$ and $1.53 \mathrm{~mm} \mathrm{Hg}$ for girls (tables 2-5). The SBP increment was $2 \mathrm{~mm} \mathrm{Hg}$ up to the age of 11 years in girls, and then decreased to $1 \mathrm{~mm} \mathrm{Hg}$ from 12 to 19 years as the girls showed a sudden increase in height at puberty (table 5).

The average annual increases in DBP for boys and girls were $0.95 \mathrm{~mm} \mathrm{Hg}$ and $0.74 \mathrm{~mm} \mathrm{Hg}$, respectively. There was a sharp increase in DBP from 17 to 19 years of age (tables 6-9).

There was a strong positive correlation between SBP and DBP with height and weight in both sexes. Concerning boys, the coefficients of correlation of SBP and DBP with height were $0.98(\mathrm{p}<0.001)$ and $0.98(\mathrm{p}<0.001)$ and with weight $0.98(\mathrm{p}<0.001)$ and $0.95(\mathrm{p}<0.001)$, respectively, while in girls the coefficients of correlation of SBP and DBP with height were $0.99(\mathrm{p}<0.001)$ and $0.98(\mathrm{p}<0.001)$ 
Table 4 Exact percentile values for systolic blood pressure (SBP) measurements in Egyptian girls from birth to 24 months of age

\begin{tabular}{|c|c|c|c|c|}
\hline \multirow[b]{2}{*}{ Age (month) } & \multicolumn{4}{|c|}{ Percentile values for SBP $(\mathrm{mm} \mathrm{Hg})$} \\
\hline & $50 \%$ & $75 \%$ & $90 \%$ & $95 \%$ \\
\hline 0 & 88 & 95 & 100 & 104 \\
\hline 1 & 88 & 95 & 100 & 104 \\
\hline 2 & 88 & 95 & 101 & 105 \\
\hline 3 & 88 & 95 & 101 & 105 \\
\hline 4 & 89 & 96 & 101 & 105 \\
\hline 5 & 89 & 96 & 102 & 106 \\
\hline 6 & 89 & 96 & 102 & 106 \\
\hline 7 & 89 & 96 & 102 & 106 \\
\hline 8 & 90 & 97 & 102 & 107 \\
\hline 9 & 90 & 97 & 103 & 107 \\
\hline 10 & 90 & 97 & 103 & 107 \\
\hline 11 & 90 & 97 & 103 & 107 \\
\hline 12 & 91 & 98 & 104 & 108 \\
\hline 13 & 91 & 98 & 104 & 108 \\
\hline 14 & 91 & 98 & 104 & 108 \\
\hline 15 & 91 & 98 & 104 & 108 \\
\hline 16 & 92 & 99 & 105 & 109 \\
\hline 17 & 92 & 99 & 105 & 109 \\
\hline 18 & 92 & 99 & 105 & 110 \\
\hline 19 & 92 & 99 & 106 & 110 \\
\hline 20 & 93 & 100 & 106 & 110 \\
\hline 21 & 93 & 100 & 106 & 110 \\
\hline 22 & 93 & 100 & 107 & 111 \\
\hline 23 & 93 & 100 & 107 & 111 \\
\hline 24 & 93 & 100 & 107 & 111 \\
\hline
\end{tabular}

and with weight $0.97(\mathrm{p}<0.001)$ and $0.91 \quad(\mathrm{p}<0.001)$, respectively.

The 90th percentile of SBP and DBP in the present study was compared for each age with the results reported in the study of the Second Task Force and Turkish children ${ }^{13}$ and the Report of the Second Task Force on Blood Pressure Control in Children in the USA. ${ }^{14}$ In boys, the 90th percentiles of SBP in Egyptian children were higher than in American children in the first 13 years, then became lower. Turkish children were higher than Egyptian children from 3 to 11 years, then became lower. The 90th percentiles for SBP in Egyptian girls were higher than in both American and Turkish girls of all ages. The DBP of American boys was lower than the Egyptians until the age of 16 years, then the DBP became higher, while the DBP of Turkish boys was lower than the Egyptians until the age of 5 years, then disclosed a significant rise. Both American and Turkish girls showed decreased DBP when compared with Egyptian girls, but this decrease exhibited
Table 5 Exact percentile values for systolic blood pressure (SBP) measurements in Egyptian girls from 1 to 19 years of age

\begin{tabular}{ccccc}
\hline & \multicolumn{4}{c}{ Percentile values for SBP $(\mathbf{m m ~ H g})$} \\
\cline { 2 - 5 } Age (year) & $\mathbf{5 0 \%}$ & $\mathbf{7 5 \%}$ & $\mathbf{9 0 \%}$ & $\mathbf{9 5 \%}$ \\
\hline 1 & 91 & 98 & 104 & 108 \\
\hline 2 & 93 & 100 & 107 & 111 \\
3 & 96 & 103 & 109 & 115 \\
4 & 98 & 105 & 112 & 117 \\
5 & 100 & 107 & 114 & 119 \\
\hline 6 & 102 & 109 & 115 & 121 \\
\hline 7 & 103 & 111 & 117 & 123 \\
\hline 8 & 105 & 112 & 119 & 124 \\
\hline 9 & 107 & 114 & 120 & 126 \\
10 & 109 & 116 & 122 & 128 \\
\hline 11 & 111 & 118 & 124 & 130 \\
12 & 112 & 119 & 125 & 131 \\
\hline 12 & 113 & 120 & 126 & 132 \\
\hline 14 & 114 & 121 & 127 & 133 \\
\hline 15 & 115 & 122 & 128 & 134 \\
\hline 16 & 116 & 123 & 129 & 135 \\
\hline 17 & 117 & 124 & 130 & 136 \\
\hline 18 & 118 & 125 & 131 & 137 \\
\hline 19 & 119 & 125 & 132 & 137 \\
\hline
\end{tabular}

an increase at the age of 12 years in American girls and at the age of 8 years in Turkish girls (figures 9-12).

\section{DISCUSSION}

Hypertension is considered one of the main health problems all over the world due to its high occurrence and its causal relationship with morbidity and mortality. ${ }^{15}$ Estimation of BP in children and adolescents should be a chief vital domain of global healthcare. BP in children varied with age and physical mass. $\mathrm{BP}$ values should be matched with normal percentile curves before concluding its normality. The distribution of BP levels and the frequency of hypertension vary in different ethnic groups. ${ }^{10} 11$ The inclusion of BP measurements in the regular paediatric examination besides the establishment of national norms in children promotes discovery of asymptomatic hypertension attributable to previously unidentified disorders. In addition, it confirms that a slight increase in BP during childhood more commonly occurred than previously realised, predominantly in adolescents. ${ }^{16}$ The present study demonstrates that BP increases with age; however, this increase varied with different ages and from boys to girls, especially with the onset of adolescence. These findings are consistent with previous population-based studies. ${ }^{17} 18$ There was a sharp increase in DBP from 17 to 19 years, which may 
Table 6 Exact percentile values for diastolic blood pressure (DBP) measurements in Egyptian boys from birth to 24 months of age

\begin{tabular}{cllll}
\hline & \multicolumn{3}{l}{ Percentile values for DBP $(\mathbf{m m ~ H g})$} \\
\cline { 2 - 5 } Age (month) & $\mathbf{5 0 \%}$ & $\mathbf{7 5 \%}$ & $\mathbf{9 0 \%}$ & $\mathbf{9 5 \%}$ \\
\hline 0 & 52 & 58 & 63 & 67 \\
\hline 1 & 52 & 58 & 63 & 67 \\
\hline 2 & 52 & 58 & 63 & 67 \\
\hline 3 & 52 & 58 & 63 & 67 \\
\hline 4 & 53 & 59 & 64 & 68 \\
\hline 5 & 53 & 59 & 64 & 68 \\
\hline 6 & 53 & 59 & 64 & 68 \\
\hline 7 & 53 & 59 & 64 & 68 \\
\hline 8 & 54 & 60 & 65 & 69 \\
\hline 9 & 54 & 60 & 65 & 69 \\
\hline 10 & 54 & 60 & 65 & 69 \\
\hline 11 & 54 & 60 & 65 & 69 \\
\hline 12 & 55 & 61 & 66 & 70 \\
\hline 13 & 55 & 61 & 66 & 70 \\
\hline 14 & 55 & 61 & 66 & 70 \\
\hline 15 & 55 & 61 & 66 & 70 \\
\hline 16 & 56 & 62 & 67 & 71 \\
\hline 17 & 56 & 62 & 67 & 71 \\
\hline 18 & 56 & 62 & 67 & 71 \\
\hline 19 & 56 & 62 & 67 & 71 \\
\hline 20 & 57 & 63 & 68 & 71 \\
\hline 21 & 57 & 63 & 68 & 72 \\
\hline 22 & 57 & 63 & 68 & 72 \\
\hline 23 & 57 & 63 & 68 & 72 \\
\hline & 57 & 63 & 68 & 72 \\
\hline
\end{tabular}

be attributed to the stress frequently encountered during the period. The rise in $\mathrm{BP}$ with increasing age is most probably caused by the growth of the child. Many researchers believed that the most powerful determinants of normal BP are chronological age and body size influenced by height and weight. ${ }^{19}$

Research and challenges to appreciating the field of racial variations and discrepancies in the circulatory standards are encumbered by the little knowledge foundation. In the present study, the trend of SBP and DBP rise was different from that reported by the Turkish and American Second Task Force. The latter Task Force values were based on nine different populations, including African and Mexican Americans. They used the first BP reading and not the average of two readings as in our study. Because of the absence of local data, reference standards based on American children have often been used worldwide and in most low-income and middle-income countries including Egypt. Hence, the standardisation of the American norms can be
Table 7 Exact percentile values for diastolic blood pressure (DBP) measurements in Egyptian boys from 1 to 19 years of age

\begin{tabular}{cllll}
\hline \multirow{2}{*}{ Age (year) } & \multicolumn{4}{l}{ Percentile values for DBP $(\mathbf{m m ~ H g})$} \\
\hline 1 & $\mathbf{5 0 \%}$ & $\mathbf{7 5 \%}$ & $\mathbf{9 0} \%$ & $\mathbf{9 5 \%}$ \\
\hline 2 & 57 & 63 & 68 & 72 \\
3 & 55 & 61 & 66 & 70 \\
4 & 58 & 64 & 70 & 73 \\
5 & 60 & 66 & 71 & 75 \\
6 & 61 & 67 & 72 & 76 \\
\hline 7 & 62 & 68 & 73 & 77 \\
\hline 8 & 63 & 69 & 74 & 78 \\
\hline 9 & 64 & 70 & 75 & 79 \\
10 & 65 & 71 & 76 & 79 \\
11 & 65 & 71 & 77 & 80 \\
\hline 12 & 66 & 72 & 77 & 80 \\
13 & 66 & 72 & 78 & 81 \\
\hline 14 & 67 & 73 & 78 & 81 \\
15 & 68 & 73 & 79 & 82 \\
\hline 16 & 68 & 74 & 80 & 83 \\
\hline 17 & 69 & 75 & 80 & 84 \\
\hline 18 & 70 & 76 & 81 & 86 \\
\hline 19 & 71 & 77 & 82 & 88 \\
\hline
\end{tabular}

misleading and BP measurements in children should be compared with local normative BP data.

Comparing BP values of African-Americans (AAs) with those of European descent, or European Americans, AAs have higher nocturnal BP as well as a smaller difference between daytime pressures. Also the lack of night-time drop in BP seen in AAs at a very young age and that accelerates during the adolescent years may be associated with increased vascular disease frequencies in AAs and may explain the frequent early onset of vascular disease, which may be attributed to the interaction of multiple influences including genetics, lifestyle regimen and deprivation. ${ }^{20}$

It is hard to define and classify race and ethnicity. The racial differences in $\mathrm{BP}$ measurements between Egyptian children compared with Turkish and American values may be driven by multiplex determinants including gene to gene, environment to environment, and gene to environment interfaces. Environmental aspects may include stress, body weight, and sodium and potassium consumption. Among the environmental influences are social concerns that may induce stress and possibly affect many physiological operations that are difficult to be evaluated and result in many biological upsets. Other social issues such as access to insurance coverage, income, education, physical activities and other sociodemographic variables such as age, 
Table 8 Exact percentile values for diastolic blood pressure (DBP) measurements in Egyptian girls from birth to 24 months of age

\begin{tabular}{cllll}
\hline & \multicolumn{3}{l}{ Percentile values for DBP $(\mathbf{m m} \mathbf{~ H g})$} \\
\cline { 2 - 5 } Age (month) & $\mathbf{5 0 \%}$ & $\mathbf{7 5 \%}$ & $\mathbf{9 0} \%$ & $\mathbf{9 5 \%}$ \\
\hline 0 & 52 & 58 & 63 & 67 \\
\hline 1 & 52 & 58 & 64 & 67 \\
\hline 2 & 52 & 58 & 64 & 67 \\
\hline 3 & 52 & 59 & 64 & 67 \\
\hline 4 & 53 & 59 & 65 & 68 \\
\hline 5 & 53 & 59 & 65 & 68 \\
\hline 6 & 53 & 59 & 65 & 68 \\
\hline 7 & 53 & 59 & 66 & 68 \\
\hline 8 & 54 & 60 & 66 & 69 \\
\hline 9 & 54 & 60 & 66 & 69 \\
\hline 10 & 54 & 60 & 66 & 69 \\
\hline 11 & 54 & 60 & 66 & 69 \\
\hline 12 & 55 & 61 & 67 & 70 \\
\hline 13 & 55 & 61 & 67 & 70 \\
\hline 14 & 55 & 61 & 67 & 70 \\
\hline 15 & 55 & 61 & 67 & 70 \\
\hline 16 & 56 & 61 & 68 & 70 \\
\hline 17 & 56 & 62 & 68 & 71 \\
\hline 18 & 56 & 62 & 68 & 71 \\
\hline 19 & 56 & 62 & 68 & 71 \\
\hline 20 & 57 & 62 & 69 & 71 \\
\hline 21 & 57 & 63 & 69 & 72 \\
\hline 22 & 57 & 63 & 69 & 72 \\
\hline 23 & 57 & 63 & 69 & 72 \\
\hline 24 & 57 & 63 & 69 & 72 \\
\hline
\end{tabular}

sex and weight (body mass index) may have less interaction with biology, but these factors have certain influences on the outcome. ${ }^{2021}$

Some researchers used an automated oscillometric device as it was easy to be used in children and to overcome the possibility of human error, but unfortunately it usually overestimates the BP matched with mercury-based sphygmomanometry. The definition of normal $\mathrm{BP}$ values in children is based on mercury sphygmomanometry, so in our study mercury sphygmomanometer was used to estimate BP measurements. ${ }^{22}$

Clinical BP recordings lean to be greater than home recordings, known as white coat hypertension. ${ }^{23}$ To record the real $\mathrm{BP}$ of subjects, the measurements were obtained in the usual settings for children, such as school and home. This variation in BP observed between different countries will postulate notable new suggestion on the variability of BP thresholds for the diagnosis and monitoring of hypertension between different ethnic clusters.
Table 9 Exact percentile values for diastolic blood pressure (DBP) measurements in Egyptian girls from 1 to 19 years of age

\begin{tabular}{cllll}
\hline & \multicolumn{4}{l}{ Percentile values for DBP $(\mathbf{m m ~} \mathbf{~ g g})$} \\
\cline { 2 - 5 } Age (year) & $\mathbf{5 0 \%}$ & $\mathbf{7 5 \%}$ & $\mathbf{9 0} \%$ & $\mathbf{9 5 \%}$ \\
\hline 1 & 55 & 61 & 67 & 70 \\
2 & 57 & 63 & 69 & 72 \\
3 & 59 & 65 & 71 & 74 \\
4 & 61 & 67 & 73 & 76 \\
5 & 62 & 68 & 74 & 77 \\
6 & 63 & 69 & 75 & 78 \\
\hline 7 & 64 & 70 & 76 & 79 \\
8 & 65 & 70 & 77 & 80 \\
9 & 65 & 71 & 77 & 80 \\
10 & 66 & 71 & 78 & 81 \\
11 & 66 & 72 & 78 & 81 \\
12 & 66 & 72 & 78 & 81 \\
12 & 67 & 72 & 79 & 82 \\
14 & 67 & 73 & 79 & 82 \\
15 & 67 & 73 & 79 & 82 \\
\hline 16 & 68 & 73 & 80 & 83 \\
\hline 17 & 68 & 74 & 80 & 83 \\
18 & 69 & 74 & 81 & 83 \\
19 & 69 & 75 & 81 & 84 \\
\hline
\end{tabular}

Until now there are no available BP nomograms for children and adolescents in Egypt. So we are one of the few academic scientific research teams to specify BP values and curves for Egyptian girls and boys.

In our study, we performed multicentric representation of diverse geographical districts in Egypt with different environments (rural and urban) and large

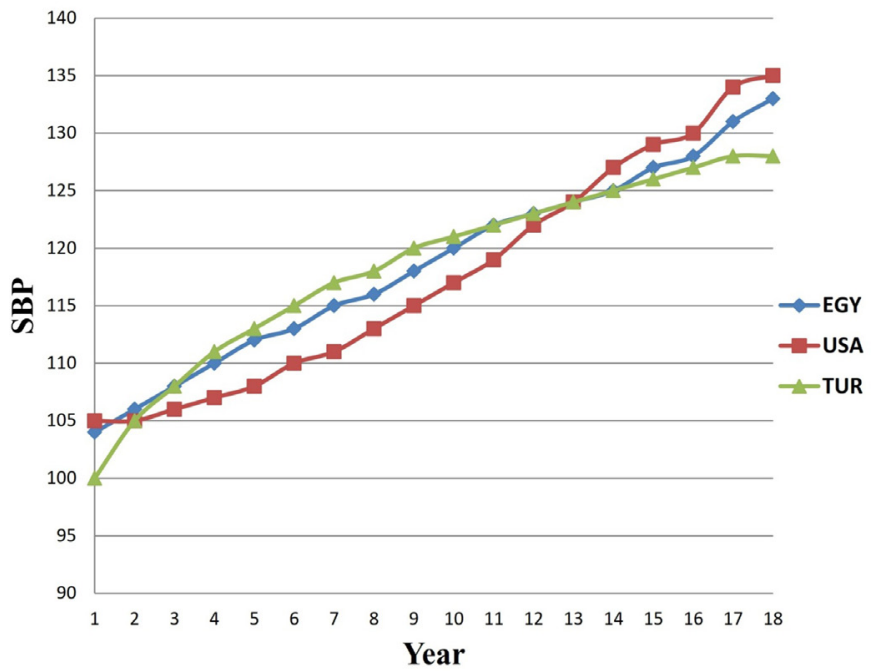

Figure 9 Comparison of the 90th percentile of systolic blood pressure (SBP) measurements of Egyptian (EGY) boys with the values of American (USA) and Turkish (TUR) boys. 


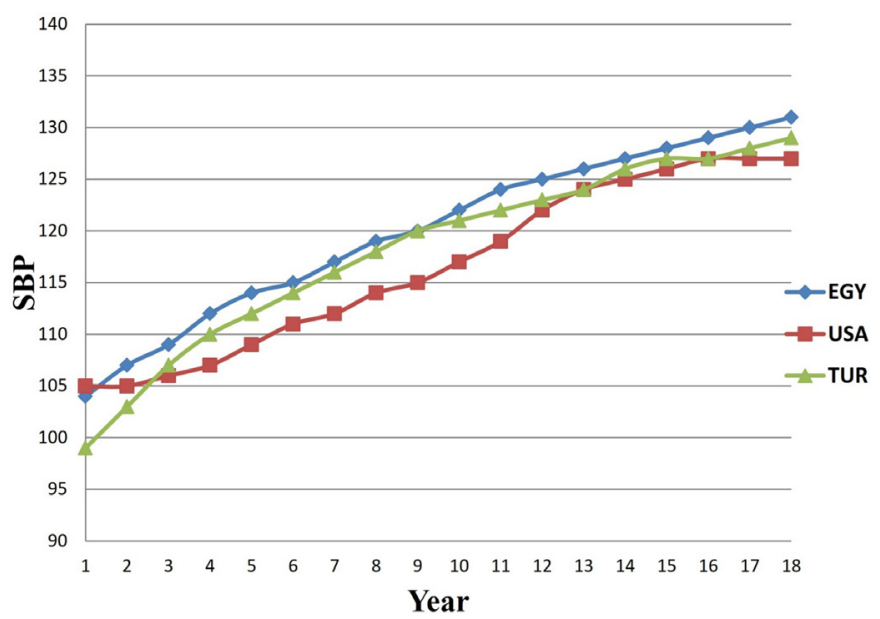

Figure 10 Comparison of the 90th percentile of systolic blood pressure (SBP) measurements of Egyptian (EGY) girls with the values of American (USA) and Turkish (TUR) girls.

sample size, and used the standard accurate mercury sphygmomanometers for $\mathrm{BP}$ records in the usual settings for children, such as school and home, overcoming the phenomenon of white coat hypertension and the inclusion of neonatal age and infancy, which were considered limitations in other studies. ${ }^{24}$ However, the exclusion of obese children in this study may create some sort of a selection bias, which may be attributed to $\mathrm{BP}$ variations between populations. Recent recommendations on the identification of high BP in children and adolescents offer BP standards based on sex, age, weight and height. Therefore, it may be essential to consider these variables during the establishment of reference BP standards in future work.

\section{CONCLUSION}

This analysis supports the hypothesis that regional differences, eating habits, differences in morphometric characteristics and other cultural factors may account for differences in BP levels during childhood. Therefore,

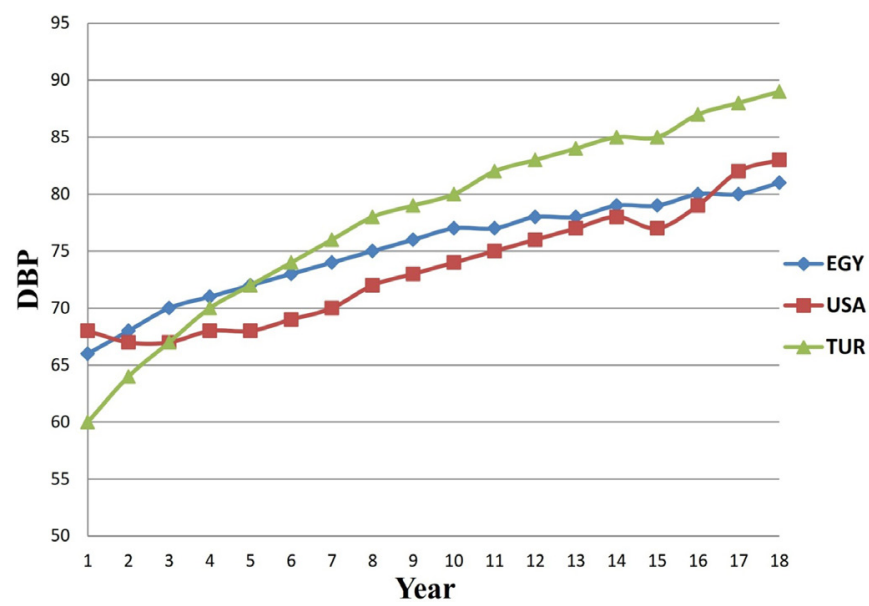

Figure 11 Comparison of the 90th percentile of diastolic blood pressure (DBP) measurements of Egyptian (EGY) boys with the values of American (USA) and Turkish (TUR) boys.

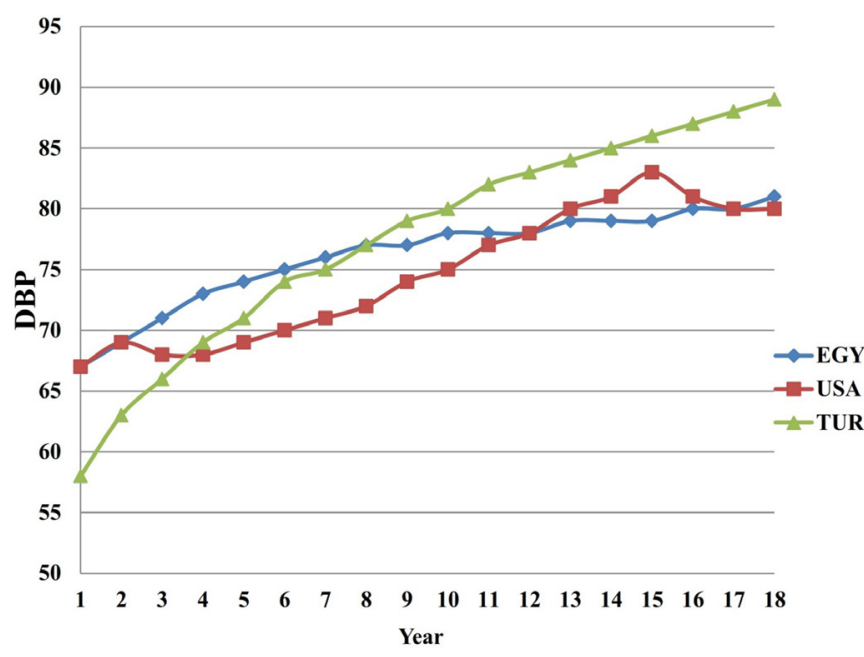

Figure 12 Comparison of the 90th percentile of diastolic blood pressure (DBP) measurements of Egyptian (EGY) girls with the values of American (USA) and Turkish (TUR) girls.

every population needs to apply its own norms to delineate a measured BP level in childhood. The BP measurements of Egyptian children and adolescents can be evaluated using the standards displayed in this scientific paper.

\section{Author affiliations}

${ }^{1}$ Department of Pediatrics, Faculty of Medicine, Menoufia University, Shebin El-Kom, Egypt

${ }^{2}$ Department of Paediatrics, Faculty of Medicine, Al-Azhar University, Cairo, Egypt ${ }^{3}$ Department of Public Health and Community Epidemiology and Biostatistics Division, Faculty of Medicine, Menoufia University, Shebin El-Kom, Egypt

${ }^{4}$ Ministry of Health Hospitals, Cairo, Egypt

Acknowledgements No words could express our deep feelings towards our patients and teamwork.

Contributors Idea and design: AME-S, FME-G, DMA, WMMAEF, SAAen, MAZ. Participant enrolment and data collection: ANE-B, MAE-nAEF, AAAE-M, AMK, HMR, GMB, AGS, WSG. Data interpretation: ZAO, MAS, WAB. Manuscript writing: ZAO, MAS, WAB, WMMAEF. Statistical analysis: ZAK. Manuscript revision: RSEZ, NMSAEH, BAEG. Final approval of the submitted manuscript: all authors.

Funding This research received no specific grant from any funding agency in the public, commercial or not-for-profit sectors.

Competing interests None declared.

Patient consent Not required.

Ethics approval All procedures performed in the study were approved and were in accordance with the ethical standards of Menoufia University institutional research committee.

Provenance and peer review Not commissioned; externally peer reviewed. Data sharing statement No additional data are available.

Open access This is an open access article distributed in accordance with the Creative Commons Attribution Non Commercial (CC BY-NC 4.0) license, which permits others to distribute, remix, adapt, build upon this work non-commercially, and license their derivative works on different terms, provided the original work is properly cited, appropriate credit is given, any changes made indicated, and the use is non-commercial. See: http://creativecommons.org/licenses/by-nc/4.0/.

\section{REFERENCES}

1. Ogedegbe G, Pickering T. Principles and techniques of blood pressure measurement. Cardiol Clin 2010;28:571-86. 
2. Jackson LV, Thalange NK, Cole TJ. Blood pressure centiles for Great Britain. Arch Dis Child 2007;92:298-303.

3. Rosner B, Cook NR, Daniels S, et al. Childhood blood pressure trends and risk factors for high blood pressure: the NHANES experience 1988-2008. Hypertension 2013;62:247-54.

4. Barba G, Buck C, Bammann K, et al. Blood pressure reference values for European non-overweight school children: the IDEFICS study. Int J Obes 2014;38 Suppl 2(Suppl2):S48-S56.

5. Falkner B, Gidding SS, Portman R, et al. Blood pressure variability and classification of prehypertension and hypertension in adolescence. Pediatrics 2008;122:238-42.

6. Rosner B, Prineas RJ, Loggie JM, et al. Blood pressure nomograms for children and adolescents, by height, sex, and age, in the United States. J Pediatr 1993;123:871-86.

7. Hohn AR, Dwyer KM, Dwyer JH. Blood pressure in youth from four ethnic groups: the Pasadena Prevention Project. J Pediatr 1994;125:368-73.

8. Menghetti E, Virdis R, Strambi M, et al. Blood pressure in childhood and adolescence: the Italian normal standards. Study Group on Hypertension' of the Italian Society of Pediatrics'. J Hypertens 1999;17:1363-72.

9. Doll S, Paccaud F, Bovet P, et al. Body mass index, abdominal adiposity and blood pressure: consistency of their association across developing and developed countries. Int J Obes Relat Metab Disord 2002;26:48-57

10. Goonasekera CD, Dillon MJ. Measurement and interpretation of blood pressure. Arch Dis Child 2000;82:261-5.

11. Al Salloum AA, El Mouzan MI, Al Herbish AS, et al. Blood pressure standards for Saudi children and adolescents. Ann Saudi Med 2009;29:173-8.

12. Ataei N, Aghamohammadi A, Tayebi M, Yousefi E, et al. Blood pressure nomograms for school children in Iran. Pediatric Nephrology 2004;19:164-8.

13. Tümer N, Yalçinkaya F, Ince E, et al. Kara N, Ozkaya N, Ensari C, Onder S. Blood pressure nomograms for children and adolescents in Turkey. PediatrNephrol 1999;13:438-43.
14. Report of the Second Task Force on Blood Pressure Control in Children -1987. Task Force on Blood Pressure Control in Children. National Heart, Lung, and Blood Institute, Bethesda, Maryland. Pediatrics 1987;79:1-25.

15. Chow CK, Teo KK, Rangarajan S, et al. Prevalence, awareness, treatment, and control of hypertension in rural and urban communities in high-, middle-, and low-income countries. JAMA 2013;310:959-68.

16. Dekkers JC, Snieder H, Van Den Oord EJ, et al. Moderators of blood pressure development from childhood to adulthood: a 10-year longitudinal study. J Pediatr 2002;141:770-9.

17. Ataei N, Hosseini M, Fayaz M, et al. Blood pressure percentiles by age and height for children and adolescents in Tehran, Iran. J Hum Hypertens 2016;30:268-77.

18. Banker A, Bell C, Gupta-Malhotra M, et al. Blood pressure percentile charts to identify high or low blood pressure in children. BMC Pediatr 2016;16:98.

19. National High Blood Pressure Education Program Working Group on Hypertension Control in Children and Adolescents. Update on the 1987 Task Force report on high blood pressure in children and adolescents: A working group report from the National High Blood Pressure Education Program. Pediatrics 1996;98:649-58.

20. Jones DW, Hall JE. Racial and ethnic differences in blood pressure: biology and sociology. Circulation 2006;114:2757-9.

21. Frist WH. Overcoming disparities in U.S. health care. Health Aff 2005;24:445-51.

22. Frese EM, Fick A, Sadowsky HS. Blood pressure measurement guidelines for physical therapists. Cardiopulm Phys Ther $J$ 2011;22:5-12.

23. Vaindirlis I, Peppa-Patrikiou M, Dracopoulou M, et al. "White coa hypertension" in adolescents: increased values of urinary cortisol and endothelin. J Pediatr 2000;136:359-64.

24. Cantinotti M, Giordano R, Scalese M, et al. Strengths and limitations of current pediatric blood pressure nomograms: a global overview with a special emphasis on regional differences in neonates and infants. Hypertens Res 2015;38:577-87. 